\title{
Quality of Life (QOL) Assessment among Advance Cancer Patient Undergoing Palliative Treatment in Malaysia: A Social Work Perspective
}

\author{
Wanda Kiyah George Albert ${ }^{1}$, Adi Fahrudin ${ }^{2,3, *}$ \\ ${ }^{1}$ Social Work Program, Faculty of Psychology and Education, University Malaysia Sabah, Malaysia \\ ${ }^{2}$ Faculty of Social and Political Science, University of Muhammadiyah Jakarta, Indonesia \\ ${ }^{3}$ Social Work Program, Faculty of Psychology and Education, University Malaysia Sabah, Malaysia
}

\begin{abstract}
Palliative treatment is the best treatment for advanced cancer patients improve their quality of life (QOL). There is a lack of local data on the patients' QOL among cancer patient receiving palliative treatment in a university medical center in Malaysia. This study aims to describe QOL among patients with advance cancer disease receiving palliative treatment in a teaching hospital in Kuala Lumpur. This was a cross-sectional study that has been done with 120 of cancer patients that receiving palliative treatment using convenience sampling. The SF-36 questionnaire has been used to measures Quality of Life (QOL) across eight domains based on physically and emotionally component summary. Results showed that the highest score of QOL were observed in the Mental Component Summary (44.93 6.84) compared with Physical Component Summary at $(42.24 \pm 7.91)$. More studies are needed to investigate patients who score poorly on physical and mental component aspects to understand their needs in order to achieve better cancer care especially in social work perspective.
\end{abstract}

Keywords Palliative Treatment, Advance Cancer, Terminal Cancer, Quality of Life, Social Work Perspective

\section{Introduction}

Cancer is a chronic disease that causes misery to millions of people around the world (Fujinami et al., 2015; Meeker, Finnell, \& Othman, 2011). It is estimated that the number of cancer patients has increased every year (Fujinami et al., 2015; Kahriman \& Zaybak, 2014; Lu et al., 2010). According to World Health Organization report in 2012, cancer not only causes suffering to it patients but also bring fatality for over 8.6 billion of people. In 2012, lung cancer was reported contributing to the highest mortality in the world which is 1.59 million deaths have been reported, followed by liver cancer (745,000 deaths), stomach cancer
(723,000 deaths), colon cancer (694,000 deaths), breast cancer $(521,000$ deaths) and cancer esophageal $(400,000$ deaths). WHO has estimated that the incidence of cancer will increase by 70 per cent to 21.4 million new cancer cases will appear and 13.2 million cancer deaths per year in 2030 (WHO 2007).

An increasing number of people with cancer are not only reported in developing countries but it also reported in Southeast Asia (Kim et al., 2015; Meecharoen, Northouse, Sirapo-ngam, \& Monkong, 2013). In Malaysia there was also increasing of cancer patient, thus, making Malaysia as a developing country with high numbers of cancer patients (Loo, Woo, Chin, Yam, Ang \& Yim, 2013). Until 2001 Malaysia did not have a National Cancer Registry (NCR) to estimate the real incidence of cancer among Malaysians. The evaluation of NCR reports published from 2002 to 2006 show that the number of new cancer cases among residents in Peninsular Malaysia has decreased from 26,089 to 21,773. Despite the declining in the new cases, presentations at an advanced stage are still on the rise. Although the number of cancer patients has decreased but this chronic illness still contribute to mortality (Fujinami et al., 2015; Meeker, Finnell, \& Othman, 2011).

The diagnosis of cancer can causes a great emotional impact on patients and their families especially when it progresses to an advanced stage with no prospect of cure. The physical, psychosocial and spiritual discomforts experienced by patients with cancer other comorbidities and the endless struggle during the disease will decreases quality of life (QOL). In this situation the families and health professionals should more emphasize preservation of life and maximization of comfort to increase the quality of life especially for the patients that have reached a terminal stage. Beside that the functionality in physical, cognitive, roles, self-functioning and social also decreased (Edib \& Kumarasamy, 2015; Magaji et al., 2012; Ng et al., 2015; Priscilla, Hamidin, Azhar, Noorjan, Susan, and Bahariah, ISSN: 2332-6840 (Online) 2332-6832 (Print) Copyright (C) 2017 by authors, all rights reserved. Authors agree that this article remains permanently open access under the terms of the Creative Commons Attribution License 4.0 International License 
2011; Wan Puteh Saad, Aljunid, Manaf, Rizal, Sulong \& Azrif, 2013). It may become more serious when it is in advanced stages due to their inability to manage themselves and others.

Patients with advanced cancer or inability to stand treatment due to poor performance status and high co-morbidities will be treated with palliative treatment. Palliative treatment can be divided into two aspects which is; intense palliative treatment and palliative care. Intense palliative treatment is a treatment given to a patients that have showed symptoms caused by the cancer itself where and the cancer patients could not be cured completely. Chemotherapy, radiotherapy and surgery was the treatment that was given in intense palliative treatment to reduce their pain and others symptom due to their condition. Palliative medicine is a subspecialty of medicine which is recognized by the Ministry of Health since 2005 . While palliative care is not only just focus on the patient but more toward holistic approach to the entire system, and especially with the family or close friends. Some studies have shown that palliative treatment may play a significant role in improving cancer patient's quality of life (QOL) or prolonging good QOL for reasonable time with advanced cancers (Simmonds 2000). It is interesting that up to our knowledge, there are limited studies on quality of life among advance cancer patient that receiving palliative treatment.

\section{Objective of the Study}

The aim of this study are to study the profile of advanced cancer patients receiving intense palliative treatment in a at the tertiary care center in Kuala Lumpur, to assess the domains of quality of life affected in cancer patients undergoing intense palliative treatment and to find out the contribution of sociodemographic on the QOL.

\section{Methodology}

This was a cross-sectional survey of 120 of advanced cancer patients in oncology ward and at medical social work department in one of the university medical center in Kuala Lumpur from $1^{\text {st }}$ June 2012 till $28^{\text {th }}$ February 2013. The patients that undergo palliative treatment completed the survey at the time of their initial consultation or follow-up visit. No compensation was provided to participate in the study. The study was approved by the Research Ethics Committee of the university medical center. Patients older than 18 years with advanced breast, colon, lung, prostate or others cancer and with others comorbidity were included. Advanced cancer was defined as cancer with recurrent disease, had received more than two years of chemotherapy, locally advanced disease, metastatic disease or refractory disease. Informed consent was obtained for those patients interested in participation. Demographics and clinical information were collected from each patient including Short Form Health Survey (SF-36) to assess quality of life advanced cancer patients.

The Short Form-36 (SF-36) is a 36 item questionnaire which measures Quality of Life (QOL) across eight domains, which are based on both physically and emotionally component. The eight domains that the SF-36 measures are as follows: physical functioning; role limitations due to physical health; role limitations due to emotional problems; energy/fatigue; emotional well-being; social functioning; pain; general health. A single item is also included that identifies perceived change in health, making the SF-36 a useful indicator for change in QOL over time and treatment. The eight domains of QOL will divided into physical QOL (Physical Component Summary; PCS) and mental QOL (Mental Component summary; MCS). The individual subscale scores have good internal reliability (a 5 0.72-0.85) and the instrument has been validated in cancer population and showing good validity and reliability $(\alpha=0.78-0.93)$.

\section{Result}

Table 1. Distribution of Socio-demographic characteristics of Respondents $(\mathrm{n}=120)$

\begin{tabular}{|c|c|c|}
\hline Variables & No. & Percentage (\%) \\
\hline Gender & & \\
\hline Male & 57 & 47.5 \\
\hline Female & 63 & 52.5 \\
\hline Race & & \\
\hline Malay & 58 & 48.3 \\
\hline Chinese & 53 & 44.2 \\
\hline Indian & 9 & 7.5 \\
\hline Religion & & \\
\hline Islam & 58 & 48.3 \\
\hline Buddha & 46 & 38.3 \\
\hline Hindu & 6 & 5.1 \\
\hline Christian & 10 & 8.3 \\
\hline Marital Status & & \\
\hline Married & 17 & 14.1 \\
\hline Single & 92 & 76.7 \\
\hline Widowed & 11 & 10.2 \\
\hline Level of Education & & \\
\hline Primary school & 25 & 20.8 \\
\hline Secondary school & 55 & 45.8 \\
\hline College/ University & 40 & 33.4 \\
\hline & & \\
\hline & & \\
\hline
\end{tabular}

Patient characteristics are listed in Table 1. The median age was 57 years (95\% confidence interval: 22.6 - 83.5 years). Sixty three of the 120 patients $(63 \%)$ were female. Ninety two patients (76.7) were single. The distribution of race shows fifty eight of 120 patients $(48.3 \%)$ were Malay and Islam (48.3\%). Education levels of 120 patients (55 patients; $45.8 \%$ ) showed that the majority of the patients had education from secondary school or often referred to as a high school. The median monthly household for of 120 patients was MYR 2,890.0 (interquartile range [IQR]: MYR 1465.00 to MYR 4795.00.

Data on patient disease information are listed in Table 2. Majority of 120 patients (40 patients; 33.4\%) that receiving 
palliative treatment are treated for lung cancer. Fifty nine of the 120 patients $(63 \%)$ are in stage 4 of the disease. Sixty four patients $(53.3 \%)$ were diagnosed with cancer for more than 2 years. The distribution of types of palliative treatment that patient received shows sixty one of 120 patients $(50.8 \%)$ are undergoing chemotherapy. Majority of the patients ( 83 patients; $69.1 \%$ ) does not have any illnesses like diabetes mellitus, heart problem or hypertension other than cancer disease.

Table 2. Distribution Disease Information of Respondent $(n=120)$

\begin{tabular}{|c|c|c|}
\hline Types of Cancers & No & Percentage $(\%)$ \\
\hline Breast Cancer & 24 & 20.0 \\
\hline Colon Cancer & 19 & 15.8 \\
\hline Prostate Cancer & 12 & 10.0 \\
\hline Lung Cancer & 40 & 33.4 \\
\hline Others Cancers & 25 & 20.8 \\
\hline \multicolumn{3}{|l|}{ Stage of Cancer } \\
\hline Stage 2 & 8 & 6.7 \\
\hline Stage 3 & 53 & 44.1 \\
\hline Stage 4 & 59 & 49.2 \\
\hline \multicolumn{3}{|l|}{ Duration Cancer diagnosed } \\
\hline 2 years and below & 56 & 46.7 \\
\hline More than 2 years & 64 & 53.3 \\
\hline \multicolumn{3}{|l|}{ Treatment Types received } \\
\hline Chemotherapy & 61 & 50.8 \\
\hline Radiotherapy & 30 & 25.0 \\
\hline Surgery & 18 & 15.0 \\
\hline Symptom Management & 11 & 9.2 \\
\hline \multicolumn{3}{|l|}{ Comorbidity Other Diseases } \\
\hline Hypertension & 1 & 8.0 \\
\hline Diabetes & 19 & 15.8 \\
\hline Heart disease & 10 & 11.1 \\
\hline More than one Diseases & 7 & 33.3 \\
\hline None & 83 & 21.8 \\
\hline
\end{tabular}

\section{Patients Quality of Life Based on Domains}

Table 3. Scores Obtained in SF-36 by Domain from Patients Undergoing Palliative Treatment $(\mathrm{n}=120)$

\begin{tabular}{|c|c|c|}
\hline Domains Of Quality Of Life (n=120) & Mean & SD \\
\hline Role Limitations-Emotional & 99.16 & 9.12 \\
\hline Role Limitations-Physical & 77.29 & 41.50 \\
\hline Physical function & 74.91 & 32.50 \\
\hline General Health Perceptions & 63.96 & 17.41 \\
\hline Social Function & 55.93 & 21.31 \\
\hline General Mental Health Perceptions & 52.86 & 17.80 \\
\hline Energy & 52.83 & 8.39 \\
\hline Bodily Pain & 37.02 & 14.44 \\
\hline
\end{tabular}

The results quality of life among advanced cancer patient that go for intense palliative treatment was obtained with SF-36. This SF-36 for the eight domains of QOL correlated with each other and evaluation of overall QOL will divided into physical QOL (Physical Component Summary; PCS) and mental QOL (Mental Component summary; MCS). The result showed that the highest score of QOL based on domain is role limitations due to emotional problems $(99.16 \pm 9.12)$ compared with others domain. The domain on bodily pain (37.02 \pm 14.44$)$ was showed lowest score in QOL that was experienced by advanced cancer patients. The details of the results are shown in the table 3 .

\section{Patients Quality of Life Based on Component Summary}

Summary of overall QOL that consist of two physical and mental components showed that the score of mental component summary $(44.93 \pm 6.84)$ is slightly higher compared to physical components summary $(42.24 \pm 7.91)$. The details of the results are shown in the table 4 .

Table 4. Scores Obtained in SF-36 by Component Summary from Patients Undergoing Palliative Treatment $(\mathrm{n}=120)$

\begin{tabular}{|c|c|c|}
\hline Components Of Quality Of Life (n=120) & Mean & SD \\
\hline Mental Component Summary & 44.93 & 6.84 \\
\hline Physical Component Summary & 42.24 & 7.91 \\
\hline
\end{tabular}

\section{Factors Influencing Differences QOL on Physical Component Summary and Mental Component Summary}

Table 5 showed the differences in the physical and mental components of QOL scores for the patients with advanced cancer based on their characteristic. There are significant differences in QOL (physical component summary) based on education level $(\mathrm{F}=6211 ; \mathrm{p}<0.001)$, types of cancer $(\mathrm{F}=5.962 ; \mathrm{p}<0.001)$ and total of financial support $(\mathrm{F}=3.005$ $\mathrm{p}=0.033$ ). While QOL in Mental Component Summary also showed significantly differences based on age $(\mathrm{r}=-0.386$; $\mathrm{p}<0.001)$, types of cancer $(\mathrm{F}=5.522 ; \mathrm{p}<0.001)$, duration of disease diagnosed $(\mathrm{t}=5.153 ; \mathrm{p}<0.001)$, types of treatment $(F=3.117 ; p=0.029)$ and total of financial support $(F=7.168$ $\mathrm{p}<0.001)$

Table 5. Factors Influencing the Differences Score of QOL score on Physical Component summary and Mental Component Summary of Patients Receiving Palliative Treatment $(n=120)$

\begin{tabular}{|c|c|c|}
\hline Variable & Physical Component & Mental Component \\
\hline $\mathrm{Age}^{\mathrm{a}}$ & $\mathrm{t}=0.098 ; \mathrm{p}=0.700$ & $\begin{array}{c}t=-0.386 \\
p<0.001 *\end{array}$ \\
\hline Gender $^{b}$ & $\mathrm{t}=2.474, \mathrm{p}=0.358$ & $\mathrm{t}=1.602 ; \mathrm{p}=0.112$ \\
\hline Race $^{\mathrm{c}}$ & $F=0.756 ; p=0.472$ & $F=2.599 ; p=0.107$ \\
\hline Religion $^{\mathrm{c}}$ & $\mathrm{F}=0.654 ; \mathrm{p}=0.582$ & $F=0.933 ; p=0.427$ \\
\hline Marital Status $^{\mathrm{c}}$ & $\mathrm{F}=0.073 ; \mathrm{p}=0.930$ & $\mathrm{~F}=0.056 ; \mathrm{p}=0.830$ \\
\hline Education Level & $\mathrm{F}=6.211 ; \mathrm{p}<0.001 *$ & $\mathrm{~F}=2.032 ; \mathrm{p}=0.136$ \\
\hline $\begin{array}{l}\text { Monthly Household } \\
\text { Income }^{\mathrm{a}}\end{array}$ & $\mathrm{t}=0.043 ; \mathrm{P}=0.640$ & $\mathrm{t}=0.046 ; \mathrm{P}=0.617$ \\
\hline Types of Cancers ${ }^{c}$ & $\mathrm{~F}=5.962 ; \mathrm{p}<0.001^{*}$ & $\mathrm{~F}=5.522: \mathrm{p}<0.001 *$ \\
\hline Stages of Cancer & $\mathrm{t}=0.781 ; \mathrm{p}=0.226$ & $\mathrm{t}=0.154 ; \mathrm{p}=0.878$ \\
\hline $\begin{array}{c}\text { Duration Disease } \\
\text { Diagnosed }^{\mathrm{b}}\end{array}$ & $\mathrm{t}=0.382 ; \mathrm{p}=0.425$ & $\mathrm{t}=5.153 ; \mathrm{p}<0.001^{*}$ \\
\hline $\begin{array}{c}\text { Types of } \\
\text { Treatments }^{\mathrm{c}}\end{array}$ & $\mathrm{F}=2.087 ; \mathrm{p}=0.106$ & $\mathrm{~F}=3.117 ; \mathrm{p}=0.029^{*}$ \\
\hline $\begin{array}{c}\text { Cormobiditiy } \\
\text { Others Disease }^{\mathrm{b}}\end{array}$ & $\mathrm{t}=1.961 \mathrm{p}=0.052$ & $\mathrm{t}=1.831 \mathrm{p}=0.070$ \\
\hline Support Status ${ }^{\mathrm{b}}$ & $\mathrm{t}=1.354 \mathrm{p}=0.437$ & $\mathrm{t}=1.420 \mathrm{p}=0.158$ \\
\hline $\begin{array}{l}\text { Total of Financial } \\
\text { Support }^{\mathrm{c}}\end{array}$ & $\mathrm{F}=3.005 \mathrm{p}=0.033^{*}$ & $\mathrm{~F}=7.168 \mathrm{p}<0.001 *$ \\
\hline
\end{tabular}

${ }^{a}$ independent $t$ test

${ }^{\mathrm{b}}$ ANOVA

*significant at $\mathrm{p}<0.05$ 


\section{Discussion}

Indicators for the quality of life was measured by the impact of a disease and its treatment on a patient's perceived health and functional status based on physical functioning, role limitations due to physical health; role limitations due to emotional problems; energy/fatigue, emotional well-being, social functioning, bodily pain and general health. In this study, the mean score of eight domain patient's QOL are from 43.24 to 99.16 , higher than the mean scores for study done by Yang, Sun, Lu, Pang \& Ding, (2012) to 634 of cancer patient with pain in Beijing.

In the present study, the highest score in QOL domain was observed for role limitations due to emotional and the lowest score was observed for bodily pain. Hence bodily pain domain was affected more than any domains among patient that go for palliative intense treatment. Bodily pain is often cited as the most critical symptom in cancer patients. Unrelieved pain impacts of QOL and profoundly influences the patient's ability to endure treatment, return to health as a cancer survivor, or achieve a peaceful death. Possibly of the lowest score of bodily pain domain in this study might be due to the side effect of their treatment. This possibility was supported by Black, et al., (2011) and Pooja, Mahesh, Muninarayana, Sagayaraj \& Anil (2016). He states that pain was significantly correlated with appetite, mood, quality of sleeping, fatigue, pain intensity, daily activity, side effect, general appearance, and support from family. Study by Deng, et al., (2011) and Morgan, Small, Donovan, Overcash, \& McMillan (2011) have found that the relationship between pain and QOL was reciprocal. This shows that the low score of bodily pain have relation with QOL and was proven in this study. Meanwhile, the highest score found in role limitation due to emotional was due to emotional care and support that was given by their family and the care provider at the hospital. Thus making the patients' become more motivated, accompanied and does not thinking about death.

This study show, there are significant differences QOL score on physical component summary based patient's characteristic such as patient's education level, types of cancer and total of financial support. Patient with better education will have better performance status because it may differentiate in the way of patient cope and accept their condition of their disease. This finding is consistent with previous study by Wright, Zhang, Keating, Weeks \& Prigerson (2014) and Musarezaie, Khaledi, Esfahani \& Ghaleghasemi, (2014) towards advanced cancer patients that have shown, patients who have high education will find out accurate information about their illness, as well as an appropriate amount of information and at the right time, and this could improve their experience of living with cancer. The differences in type of cancer require differentiate on the patient's treatment and this ability. Lung cancer patients was found to have low QOL in mental and physical summary compared to the other cancer due to their low of performance status that effect their ability to take care of themselves. This was supported by the findings of study by Huang, Zheng, Peng, Xu \& Wang, 2009 and Shun, Chen, Sheu, Liang, Yang \& Lai (2012) on cancer patient in China. Both the study show that lung cancer patients experienced cancer pain more often than other cancer patients. In this study also, patient who received high amount of financial support reported achieve a better QOL in physical and mental component summary compared with low amount of financial support because it can help to decreasing all of expenses in their treatment. Similarly results were also seen in various studies that in the financial support from others will support in reducing the medical and the treatment costs, thus improve their physical status (Akin, Can, Aydiner, Ozdilli \& Durna, 2010; Güner, et al., 2006).

The findings of the present study show that there are significant differences QOL in the mental component summary based on patient's age, types of cancer, duration of disease diagnosed and total of the financial support. The younger patients had higher scores in mental component summary compared to older patient due to role commitment in their life. Older cancer patients have been found have a lot commitment and taking on too many responsibilities and leading to distress, in contrast to younger patient who see that responsibility and challenge in getting any aid was their family responsibilities (Park, Lee, Lee, Lee \& Hwang, 2011;Wang, 2009). The difference QOL score in mental component also was reported in this study due to the duration of treatment. Advanced cancer patient who go for palliative intense treatment for more than two years showed lowest score in QOL in mental component. Patients with a shorter duration since diagnosis may be less able to cope with the reality of their situation and, consequently, may want their physician to make decisions regarding their care. This result was supported by Umezawa, Fujimori, Matsushima, Kinoshita \& Uchitomi (2015) in Japan population.

Based on the findings in studies, social worker should give more attention on patient's mental aspect. Although Malaysia still doesn't have any oncology social workers who specialize in oncology setting but the oncology cases can be referred to medical social workers through formal mechanisms such as by a doctor or nurse and through informal ways, by a friend or family member. Medical social workers in are the primary providers of psychosocial services in the hospital or National Cancer Institute in Malaysia using their medical setting expertise in cancer and its psychosocial impact on patients and their family. Beside that medical social workers have training in dealing with psychosocial issues such as anxiety, family relationships, changes in lifestyle during and following treatment. Social workers are also there to help patient and their family with re-integration into the work force and to cope with fears about recurrence and death which are stressors experienced by many cancer patients.

This study also shows that the financial support provided by social workers has reduced financial stressors caused by the illness and increase QOL on mental and physical 
component. It also helps patient to keep continuing the treatment without thinking about the cost that their caregiver has spent on it. The QOL of family also will be increasing because they have to full fill the patient need and their satisfaction as a caregiver.

The medical social workers in Malaysian hospital also are an important link in the chain of communication that takes place in a hospital. They also will accompany patients and their family through all phases of the illness trajectory with their skill and knowledge to assist with the psychological, social, emotional, and spiritual issues that people have to deal with in health setting including oncology setting. Medical social worker will help patients, families, and caregivers deal with practical needs, like finding resources in the institution and the community, and with such complex needs such as adjusting to an illness, dealing with transitions and decision-making, navigating cultural issues, and communicating with family members, friends, and health care providers. An involving of medical social worker will help improve quality of life among patient and their family that receiving palliative treatment in Malaysian hospital.

Further research is needed to evaluate others aspects in patients with advanced cancer and other chronic illnesses. Some tools, such as the comprehensive score specific for QOL in advanced cancer patient or palliative care need to be done because it will help us better understand what is happening to the patients and identify possible interventions to ease their suffering and improve their quality of life. More research also needs to be done to validate it in larger samples or other settings and address the possible causality during the trajectory of the illness. Also, we cannot generalize our results, since only one institution were involved; further studies would need to be developed at a higher scale, including private and public hospitals. Our results strongly support that patient's sociodemographic such as financial support should be regularly measured in all patients with advanced cancer attending to palliative treatment services because it is the modified factor that always been a main factor for patient to keep on their treatment.

\section{Conclusions}

In conclusion, the results of this study highlight the quality of life among advanced cancer patients that go for intense palliative treatment. These results have significant implications for better understanding about circumstances in advanced cancer patients especially on their level of QOL. A negative stigma attached to the label "palliative treatment" associated with death and with care at the very end of life among advanced cancer patients, families and healthcare providers, which provoked their fear and avoidance impedes earlier access to supportive care that can improves quality of life.

Advanced cancer patients undergoing treatment suffer many limitations due to an array of symptoms and disruptions in various areas of QOL, arising from both the disease process and its treatment. So, more studies are recommended to provide QOL measurements in advanced cancer patient and to allow a better understanding of the contribution of the sociodemographic characteristics of the patients to their quality of life. This can provide an objective basis for informing decision making for social worker and others health provider, like in which area more attention is needed for a particular patient, and for making the case for allocation of appropriate resources to medical and supportive services.

\section{REFERENCES}

Akin, S., Can, G., Aydiner, A., Ozdilli, K., \& Durna, Z. (2010). Quality of life, symptom experience and distress of lung cancer patients undergoing chemotherapy. European Journal of Oncology Nursing, 14(5), 400-409.

Black, B., Herr, K., Fine, P., Sanders, S., Tang, X., Bergen Jackson, K., \& Forcucci, C. (2011). The relationships among pain, nonpain symptoms, and quality of life measures in older adults with cancer receiving hospice care. Pain Medicine, 12(6), 880-889.

Deng, D., Fu, L., Zhao, Y. X., Wu, X., Zhang, G., Liang, C...., \& Zhou, Y. F. (2011). The relationship between cancer pain and quality of life in patients newly admitted to Wuhan Hospice Center of China. American Journal of Hospice and Palliative Medicine, 1049909111418636.

Fujinami, R., Sun, V., Zachariah, F., Uman, G., Grant, M., \& Ferrell, B. (2015). Family caregivers' distress levels related to quality of life, burden, and preparedness. Psycho - Oncology, 24(1), 54-62.

Fujinami, R., Sun, V., Zachariah, F., Uman, G., Grant, M., \& Ferrell, B. (2015). Family caregivers' distress levels related to quality of life, burden, and preparedness. Psycho - Oncology, 24(1), 54-62.

Güner, P., Isikhan, V., Kömürcü, S., Il, S., Öztürk, B., Arpaci, F., \& Özet, A. (2006). Quality of life and sociodemographic characteristics of patients with cancer in Turkey. In Oncology nursing forum (Vol. 33, No. 6).

Kahriman, F., \& Zaybak, A. (2014). Caregiver Burden and Perceived Social Support among Caregivers of Patients with Cancer. Asian Pacific journal of cancer prevention: APJCP, 16(8), 3313-3317.

Kim, Ryn, M., Jensen, R. E., Griffin, J. M., Potosky, A., \& Rowland, J. (2015a). Effects of gender and depressive symptoms on quality of life among colorectal and lung cancer patients and their family caregivers. Psycho - Oncology, 24(1), 95-105.

Loo, J. L., Woo, W. Y., Chin, M. W., Yam, H. R., Ang, Y. K., \& Yim, H. S. (2013). Cancer Awareness of a Sample of Malaysian Undergraduate Students. American Journal of Cancer Prevention, $1(1), 9-13$.

Mansano-Schlosser, T. C., \& Ceolim, M. F. (2012). Quality of life of cancer patients During the Chemotherapy Period. Texto \& Contexto-Enfermagem, 21(3), 600- 607. 
Meecharoen, W., Northouse, L. L., Sirapo-ngam, Y., \& Monkong, S. (2013). Family Caregivers for Cancer Patients in Thailand. SAGE Open, 3(3), 2158244013500280.

Meeker, M. A., Finnell, D., \& Othman, A. K. (2011). Family caregivers and cancer pain management: a review. Journal of family nursing, 17(1), 29-60.

Musarezaie, A., Khaledi, F., Esfahani, H. N., \& Ghaleghasemi, T. M. (2014). Factors affecting quality of life and fatigue in patients with leukemia under chemotherapy. Journal of education and health promotion, 3(1), 64.

Morgan, M. A., Small, B. J., Donovan, K. A., Overcash, J., \& McMillan, S. (2011). Cancer patients with pain: the spouse/partner relationship and quality of life. Cancer nursing, 34(1), 13.

Park, B. W., Lee, S., Lee, A. R., Lee, K. H., \& Hwang, S. Y. (2011). Quality of life differences between younger and older breast cancer patients. Journal of breast cancer, 14(2), 112-118.

Pooja, R.S., Mahesh, V., Muninarayana, Sagayaraj \& Anil, N. S. (2016). Quality of life assessment among cancer patients undergoing treatment in a rural tertiary care center. Journal of Preventive Medicine and Holistic Health, 2(2), 36-40
Umezawa, S., Fujimori, M., Matsushima, E., Kinoshita, H., \& Uchitomi, Y. (2015). Preferences of advanced cancer patients for communication on anticancer treatment cessation and the transition to palliative care. Cancer, 121(23), 4240-4249.

Wang, H. (2009). Assessment of the nutritional status and quality of life of the elderly patients with malignant tumor by MNA-SF and SF-36 [J]. Journal of Tongji University (Medical Science), 3, 033.

Wright, A. A., Zhang, B., Keating, N. L., Weeks, J. C., \& Prigerson, H. G. (2014). Associations between palliative chemotherapy and adult cancer patients' end of life care and place of death: prospective cohort study. BMJ, 348, g1219.

World Health Organization. (2014). Cancer. (WHO Media Centre-Fact sheets). Geneva, Switzerland: Author.

Yang, P., Sun, L. Q., Lu, Q., Pang, D., \& Ding, Y. (2012). Quality of life in cancer patients with pain in Beijing. Chinese Journal of Cancer Research, 24(1), 60-66. 